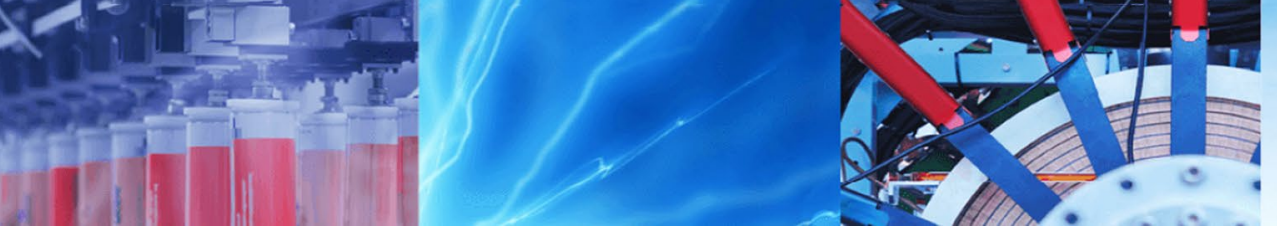

Correction

\title{
Correction to: Constructing a spatial analysis model in assessing the sensitivity of landscape erosion in mountainous regions of Vietnam
}

\author{
Quoc Lap Kieu ${ }^{1} \cdot$ Thi Van Huong $\mathrm{Do}^{2} \cdot$ Huu Tap $\operatorname{Van}^{1}$ (I)
}

Published online: 26 October 2020

(c) Springer Nature Switzerland AG 2020

\section{Correction to: SN Applied Sciences (2020) 2:1743 https://doi.org/10.1007/s42452-020-03558-5}

There was an error in the map in Fig. 1 (Study area of Ngu Chi Son, Vietnam). It is replaced with Fig $1 \mathrm{~S}$ in the electronic supplementary material.
Correction reason: To add Hoang Sa and Truong Sa archipelagos according to the Law of Vietnamese government.

Publisher's Note Springer Nature remains neutral with regard to jurisdictional claims in published maps and institutional affiliations.

Electronic supplementary material The online version of this article (https://doi.org/10.1007/s42452-020-03655-5) contains supplementary material, which is available to authorized users.

The original article can be found online at https://doi.org/10.1007/s42452-020-03558-5.

$\triangle$ Huu Tap Van, tapvh@tnus.edu.vn | ${ }^{1}$ Faculty of Natural Resources and Environment, TNU-University of Sciences, Tan Thinh ward, Thai Nguyen, Vietnam. ${ }^{2}$ Faculty of Tourism, TNU-University of Sciences, Tan Thinh ward, Thai Nguyen, Vietnam. 